\title{
Development of a Semiconductor-Based Electrochemical Sensor for Interferon- $\gamma$ Detection
}

\author{
Zhihui Chu, Haiyan Dai, Yingwei Liu and Yuhua Lin * \\ Department of Ophtalmology, Hongqi Hospital Affiliated to Mudanjiang Medical University, No.5 \\ Tongxiang Rd, Aimin, Mudanjiang, Heilongjiang, 157000, P.R. China \\ *E-mail: linyuhua36@163.com
}

doi: $10.20964 / 2017.10 .85$

Received: 12 July 2017 / Accepted: 26 August 2017 / Published: 12 September 2017

This report described an excellent method for interferon gamma (IFN $\gamma$ ) detection using a label-free electrochemical impedance immunosensor. $\mathrm{TiO}_{2}$ NPs prepared using a simple hydrothermal strategy were applied to the immobilization of the IFN $\gamma$ monoclonal antibody. The relative increase in the impedance value was proportional to the logarithmic value of the IFN $\gamma$ concentration $(0.001$ $0.2 \mathrm{ng} / \mathrm{mL}$ ), and the limit of detection (LOD) was calculated as $0.74 \mathrm{pg} / \mathrm{mL}$. This work presented a facile, novel and highly sensitive strategy.

Keywords: Interferon gamma; Semiconductor; $\mathrm{TiO}_{2} \mathrm{NPs}$; Immunosensor; Electrochemical impedance spectroscopy

\section{$\underline{\text { FULL TEXT }}$}

(C) 2017 The Authors. Published by ESG (www.electrochemsci.org). This article is an open access article distributed under the terms and conditions of the Creative Commons Attribution license (http://creativecommons.org/licenses/by/4.0/). 